\title{
El retorno a los bosques encan- tados: infancia y monstruosidad en ficciones del sur
}

\section{The Return to the Haunted Forests: Infancy and Monstrosity in the Fictions of the South}

\author{
María José Punte \\ Pontificia Universidad Católica Argentina \\ majo.punte@gmail.com
}

\section{Resumen:}

En este artículo se abordará una serie de novelas de la narrativa producida recientemente en el ámbito del Cono Sur (Argentina y Chile), que tienen en común la recreación de un universo infantil, inspirada en los cuentos de hadas tradicionales. Lo notable en todos los casos es que dicha aproximación se caracteriza por resaltar los aspectos ominosos del imaginario de la infancia, mediante la configuración de una mirada que se aproxima a ese universo a partir de lo monstruoso.

Palabras clave: novelas del Cono Sur, infancia, cuentos de hadas, biopolítica.

\section{Abstract:}

This article deals with three novels from the Southern Cone's recent production. All of them have in common the recreation of a universe originally shaped in traditional fairy tales. It is remarkable in very case that said approximation is characterized by highlighting ominous aspects of infancy, by configuring a gaze that approaches that universe from the perspective of monstrosity.

Keywords: Novels from The Southern Cone, Childhood, Fairy Tales, Bio-political. 
El viaje de Caperucita es un tránsito, una verdadera travesía que va de la condición de púber a la de abuela. El bosque es en realidad el tiempo a lo largo del cual se van cosechando experiencias (para meterlas en la canastita).

Luisa Valenzuela, "Ventana de hadas".

El tópico de la infancia vuelve en la literatura reciente del Cono Sur con un efecto revulsivo inesperado y una pulsión libidinal intensa. Salta a la vista en contraste con los paisajes kitsch de libros que todos recordamos desde nuestras postales de la niñez. El epígrafe tomado de un texto de la escritora argentina Luisa Valenzuela permite asomarnos a una matriz de interpretación ya clásica, en la que emerge aquello inquietante que se esconde tras lo intrascendente y lo abismal tras lo miniaturizado. Este artículo nos permitirá concentrarnos en unos pocos textos que tienen en común un llamativo aire de familia. Toma la forma de la construcción de una mirada de la infancia a partir de una iconografía precisa, que remite a los así llamados cuentos de hadas. Los textos a considerar son tres novelas publicadas en Chile y Argentina: La batalla del calentamiento (2006) del argentino Marcelo Figueras; Wakolda (2011) de su compatriota Lucía Puenzo; y Las infantas (1998) de la narradora chilena Lina Meruane ${ }^{1}$. Si bien Valenzuela ya había tratado la cuestión en sus Cuentos de Hades (1993), su pertenencia a una generación anterior definía un enfoque que implicaba otras preocupaciones tanto estéticas como temáticas. La intención de deconstruir los relatos infantiles desde la irreverencia y el humor, y desde premisas explícitamente feministas, abrió un camino a seguir que la siguiente generación continúa a su manera. Estos textos toman la posta para proseguir con ese viaje de Caperucita, internando a los lectores nuevamente en los bosques de la infancia.

Rescatamos de la cita la topografía del bosque en tanto que metonimia de un paisaje, el de los países encantados de los cuentos infantiles. No solo por lo que supone como construcción de una determinada temporalidad, lo que plantea Valenzuela instalando un cronotopo particular, sino por los significados que se anudan a esa geografía y que son configuradores de las tres novelas. En una primera dimensión de corte vertical, resulta central la noción de profundidad ligada a los abismos, es decir, a los aspectos ominosos que transitan la infancia en oposición con una supuesta claridad o inocencia. Por otra parte, desde el punto de vista de la horizontal, su carácter de espacio lleno y a la

1 El texto Las infantas fue publicado en Chile en el año 1998 por editorial Planeta. En Argentina apareció bajo el sello Eterna Cadencia en el 2011. Además de esta primera obra, Meruane publicó las novelas Póstuma (2000), Cercada (2000), Fruta podrida (2007) y Sangre en el ojo (2012), así como numerosos cuentos en antologías y revistas. Lucía Puenzo ha publicado las novelas 9 minutos (2005), La maldición de Jacinta Pichimahuida (2007), El niño pez (2008) y La furia de la langosta (2010). Como directora de cine, realizó dos largometrajes: XXY (2007) y El niño pez (2009). Es autora de numerosos guiones, al igual que Marcelo Figueras. Por su parte, Figueras lleva publicadas, además de La batalla del calentamiento, las novelas El muchacho peronista (1993), El espía del tiempo (2002), Kamchatka (2003) y Aquarium (2009). 
vez plagado de ambigüedades hace referencia a un sistema de representaciones específico en lo relativo al cuerpo, que expone el modo en que la sociedad tiende a jerarquizar o valorizar algunos cuerpos por encima de otros. El bosque funciona como un lugar que da albergue a los monstruos y a toda clase de especies anormales, o desviadas de la especie. Por eso resulta peligroso. Es en sí mismo una topografía monstruosa, en la medida en que genera significados potencialmente contradictorios y que desafían toda reducción racionalista, tal y como plantea Rosi Braidotti a propósito de la monstruosidad ("Signs of wonder” 135). En ese sentido, también se puede comprender su uso admonitorio, ya que al igual que los monstruos, a partir de la conjunción de esferas antagónicas que aúnan en el imaginario lo sagrado y lo profano, o lo terreno y lo sobrenatural, el bosque se planta como territorio de la advertencia (Braidotti, "Signs of wonder" 136$)^{2}$.

El funcionamiento de esta topografía se presenta como polisémica. Dispara interpretaciones que parecen antagónicas, pero que son afines con los modos de experimentar los conflictos que quedaron plasmados en los relatos infantiles tradicionales ${ }^{3}$. Así como con la posibilidad insinuante de resolverlos mediante el recurso del vericueto. Sin embargo, parte de esa polisemia es su rasgo normalizador, sobre todo en las codificaciones que llegaron hasta nuestros días. Los cuentos de hadas suelen trabajar, entre otras cosas, a partir del topos literario que traza una correlación entre determinadas características físicas con rasgos morales precisos (Detrez 14). El orden deseado y deseable reposa sobre la adecuación entre belleza, honestidad y rango. Las descripciones literarias no hacen otra cosa que poner en obra representaciones dominantes, que circulan por otros ámbitos discursivos más asépticos, sean estos filosóficos o científicos (16). Al pensar al cuerpo como algo dado desde la biología, se justifican las posiciones sociales y el orden sobre el cual reposan. Volver a esos paisajes con el objetivo de leer a contrapelo los relatos que nos acompañaron en un estadio fundamental de la vida, permite revisar ese sistema de representaciones. Pero también recuperar cierta potencia de la fantasía como moldeadora de las subjetividades. En gran medida, como veremos, los tres autores se proponen este retorno como una estrategia para hablar de una situación política concreta que todos vivieron siendo niños. A eso, se agregan cuestiones que tienen que ver con nuevos planteos sobre los cuerpos, a los que se entiende antes que nada como producto de la socialización. Tomamos la noción de paisaje, en la medida en que en ella se anudan tanto el orden de la representación como el de la vivencia (Giménez 9). El paisaje implica la percepción vivencial del territorio, el

2 Según el diccionario de símbolos de Chevalier y Gheerbrandt en varias culturas antiguas tanto europeas como asiáticas el bosque está asociado a la noción de santuario. Los árboles que lo pueblan representan un principio de vida, por lo tanto bienhechor (134-5). Es un reservorio de vida y de conocimiento o sabiduría. Pero en otra de sus acepciones más modernas, por sus aspectos de oscuridad y profundidad el bosque está ligado al inconsciente (456).

3 Díaz Rönner apunta que a partir del siglo XVIII se suscitaron determinadas estrategias tanto políticas como pedagógicas que produjeron una renovación social del estatuto del niño. A su vez, en ese mismo gesto, terminaron denostando los elementos propios de la imaginación, sobre todo aquellos que provenían del campo popular. No obstante, estos ingredientes fabulosos permanecieron resguardados en los cuentos tradicionales transcritos por Perrault y por los hermanos Grimm (117). 
cual no solo es introyectado por el ojo humano, sino también por su aparato afectivo y estético. Funciona como referente de la identidad socioterritorial (Giménez 10), al estar cargado de símbolos y de connotaciones valorativas. Los paisajes de la infancia contienen entonces restos de fantasías infantiles, pero también de prejuicios y valoraciones que se hace imprescindible desmontar, si lo que se busca es un nuevo comienzo.

\section{¿Lobo estás? O de la invitación a jugar}

En primer lugar tomaremos la novela de Marcelo Figueras, La batalla del calentamiento (2006), por ser la que a su manera más se regodea en estos paisajes de la infancia. La historia transcurre en el sur de Argentina, un espacio mitificado desde una vasta tradición narrativa. Si bien las locaciones no se corresponden con referencias físicas concretas, funcionan como analogías evidentes de lugares que existen en los mapas argentinos y que el lector puede reconocer con facilidad. El pueblo en donde se ubica gran parte de la acción se llama Santa Brígida, un lugar ficticio. Con sus chalecitos suizos, los bosques y quebradas que lo rodean, y las montañas nevadas que le sirven de marco, bien puede aludir a un espacio fantasmático, que da cuerpo al territorio del imaginario infantil. Hay algo siniestro que surge a partir de la citación y que se superpone a una territorialización más concreta: la Argentina de mediados de los años ochenta, es decir, de la transición democrática.

Una abundante intertextualidad remeda un trabajo a partir del collage, en donde se cruzan referencias cinematográficas y de la cultura pop con una variedad enorme de relatos, que de modo más o menos directo hacen referencia al universo de la infancia. Esta mezcla discursiva se liga, en principio, a la concepción que tiene Figueras sobre la acción de narrar, la creencia de que el relato de ficción, en virtud de su capacidad de fagocitar diferentes tipos de discursos, es una instancia creadora de realidad (Punte). Hay una mención a las fábulas, en el personaje del lobo que habla; a la Leyenda Dorada y a los Evangelios Apócrifos en la construcción del personaje de la niña, Miranda, para la cual se recurre también a la persona histórica de Hildegarda de Bingen'; a la película Big Fish (2003) de Tim Burton en la figura del gigante Teo. A su vez, este personaje es una analogía del Christophoro, proveniente de una leyenda medieval y muy presente en la iconografía religiosa europea. Los protagonistas de esta novela son el gigante en cuestión, Teodoro Labat y la niña, Miranda. Juntos corporizan el icono antes mencionado, el

4 Hildegarda de Bingen fue una abadesa, líder monástica, mística, médica, compositora y escritora alemana. Nació en 1098, en el valle del Rin, en el seno de una familia noble alemana, y murió en 1179. Entró al convento de Disibodenberg con catorce años. A los treinta y ocho años, y a pesar de su juventud, fue elegida abadesa. Desde niña tenía visiones. A los cuarenta y dos años esas visiones se hicieron más intensas. Se le aparecían en forma consciente y se manifestaban como imágenes y sonidos. Desde ese momento recibe la orden de redactarlas, con lo que comienza su obra escrita. En el año 1148 emprende la fundación del monasterio de Rupertsberg, al que le sigue el de Eibingen en 1165. Además de desarrollar una labor de predicadora, Hildegarda compuso setenta y ocho obras musicales, y es autora de la primera lengua artificial que se conoce, Lingua ignota. Escribió obras de carácter teológico y científico. 
del portador de Cristo ${ }^{5}$. Ambos son monstruosos. Teo, a causa de su desproporción, un hombre nacido en circunstancias muy especiales como la tradición indica para los gigantes (Chevalier 474), cuya desgracia es ser de tamaño XXXL en un mundo diseñado para XS, como se afirma en la novela. Miranda, si bien es una niña adorable, excede los límites de lo inteligido como humano. Exhibe una serie de poderes que la ubican en el campo de lo considerado anormal. No solo maneja la capacidad de captar las misteriosas armonías y desarmonías del universo, y de transcribirlas en formas de dibujos. Posee la cualidad de materializar sus deseos, sean estos buenos o malos. Esta circunstancia le adjudica una doble valencia, ya que puede actuar como sanadora o ser destructiva. Las canciones, que se suman a esta compleja trama intertextual, constituyen a su vez una forma de mediación en su comprensión del mundo exterior. Miranda decodifica sus visiones y experiencias a través del lenguaje de la música.

Teo y Miranda no están solos, sino rodeados en ese pueblo de trazos idílicos por una serie de personajes que conforman una constelación de singularidades. Para empezar, está la madre de Miranda, Pat Finnegan, una joven de ancestros irlandeses que habla con su hija en inglés. Pat fue militante política y, en el presente del relato, es una fugitiva. Su misión obsesiva y casi excluyente consiste en proteger a Miranda del hombre que la engendró, un militar involucrado en las torturas y desapariciones perpetradas por la última dictadura argentina. Este hombre las persigue por toda la geografía del país, con el único fin de adueñarse de la niña. Pat y Miranda encuentran refugio en Santa Brígida. Sus habitantes las aceptan e integran. Son gente más o menos simpática, pero atravesada por rarezas y peculiaridades. Teo, quien también va huyendo, se topa con Miranda y su madre, hecho que lo obliga a confrontar sus problemas y a cambiar el rumbo. Al hacerse cargo de la niña, al cargarla sobre sus hombros, Teo va a dar origen a una nueva forma de familia basada en la noción ya no de familia nuclear tal como la entendía la modernidad (Roudinesco 19), sino de comunidad. El planteo de la novela se centra en la idea de que familia es la que se elige. Implica construir un compromiso desde una subjetividad con los otros. Esta idea es evocada en el título, tomado de una canción-juego infantil: La batalla del calentamiento ${ }^{6}$. La cuestión de un nuevo tipo de configuración familiar se anuda a un cuestionamiento que es tanto social como político. Por las rendijas de ese paisaje de bosques y de lobos que hablan en latín, de gigantes y de duendes, de brujas y de heroínas,

5 Para construir al personaje de Miranda, Figueras asegura en la entrevista que le hace Silvina Friera haberse inspirado en los Evangelios Apócrifos, que presentan una imagen fabulada de Jesús y aspectos de su niñez no consignados en los otros evangelios. Jesús es y no es un niño como lo otros. Por un lado, hace castillos en la arena. Por el otro, este niño es narrado como poseedor de capacidades supuestamente evidentes en un dios. El hecho de tener poderes hace que la familia se vea obligada a elaborar estrategias de ocultamiento y un cierto disciplinamiento del niño.

6 Para quienes no la recuerdan o no la conocen, La batalla del calentamiento es a la vez una canción y una danza, a la que se recurre para combatir el frío. Los participantes se colocan en círculo y comienzan a moverse con un pequeño trote en el lugar. El texto comienza así: "En la batalla del calentamiento, había que ver la fuerza del jinete". Luego se interrumpe con la interpelación "Jinete, a la carga", ante la que los participantes se detienen y esperan las indicaciones del que dirige. Este indica la parte del cuerpo que habrá que mover: primero el pie, luego la mano, luego la cabeza, y así sucesivamente. La dinámica de la suma de partes hace que la danza se vaya volviendo cada vez más complicada y frenética. 
asoma una realidad política, la de la última dictadura militar y las secuelas dejadas en la sociedad civil. Mediante el borramiento de las fronteras de los géneros narrativos parece provocarse una desterritorialización, que es luego negada por una localización temporal precisa, ya que la novela transcurre entre 1982 y 1984, el momento bisagra de pasaje a la democracia. Se está hablando del tipo de comunidad que conviene a un sistema democrático, algo que se había perdido en el período anterior signado por el terror y la consiguiente falta de solidaridad.

Miranda es una niña extraordinaria; se coloca por fuera de la norma. Pero no solo por el hecho de tener una serie de cualidades, entre místicas o legendarias. Miranda se instituye en la narración en tanto que mirada de la infancia. Con esto nos referimos al concepto de infancia que plantea Giorgio Agamben en su ensayo Infancia e historia. Infancia que etimológicamente significa ausencia de habla, en una cultura que entiende a la temporalidad de manera lineal, alude también a la etapa del comienzo. Ese comienzo tiene que ver con la experiencia anterior al lenguaje, el mysterion (Agamben 71), instituido para el hombre por la infancia, por el hecho de tener una infancia. Es una instancia asociada a la apertura y a la libertad, previa a la caída en el lenguaje (Bustelo 141). Un espacio que goza, por lo tanto, de la pura potencialidad. La infancia, en tanto que comienzo, representa el "momento constitutivo del hombre" (Bustelo 142). Pero la infancia desde su etimología negativa remite también a la carencia, no solo en el terreno del habla, sino de los derechos políticos (Kohan 10). Y en ese sentido es un concepto al que se suele ligar con el de extranjería. Se establece un doble juego entre impotencia y libertad. Tanto la infancia como la extranjería inscriben al sujeto en una lógica de la ausencia y la negación. No obstante, visto desde otro punto de vista, abren un espacio que libera de lo establecido, de la rutina y la normalidad (Kohan 13). A partir de este personaje la novela plantea la posibilidad de refundar un universo, claramente ligado al país y a su historia concreta. Pero también a nuevos modo de entender tanto a la familia como a lo comunitario. Miranda recibe de su madre una herencia que resulta fundamental en términos de conformación de subjetividades nuevas. No solo la cuestión de la extranjería, en la medida en que funciona como la capacidad de vivir en más de una patria cultural. Su principal legado es aquello que se reactiva cada vez que cantan juntas La batalla del calentamiento. Esta canción funciona como una invitación a una lucha colectiva para salir del letargo y de la muerte, para poner en acto el movimiento.

\section{Casa de muñecas}

Son varios los lazos que se pueden establecer entre el texto de Figueras y Wakolda (2011), la última novela de Lucía Puenzo. En primer lugar, la puesta en escena en el sur argentino. En la novela de Puenzo la referencialidad es explícita porque transcurre mayormente en la ciudad de Bariloche, al borde del lago Nahuel Huapi. La elección de este escenario tiene mucho que ver con el trasfondo político del texto, que sigue las huellas de los exiliados 
del régimen nacional-socialista alemán, instalados en buena medida en esta ciudad antes y después de la Segunda Guerra Mundial. La novela no pretende ser realista, sino que fantasea alrededor del personaje histórico de Joseph Mengele, para indagar sobre cuestiones que van más allá de su figura. La mirada oblicua hacia la historia argentina reciente es otro elemento que ambos textos comparten. Puenzo, por otro lado, lo hace mediante un desvío hacia la historia del siglo XIX. Vuelve a poner el foco en el genocidio indígena y sus consecuencias a lo largo del siglo XX. Ya lo había hecho en El niño pez, una novela del año 2008 que su autora además llevó al cine. En este caso, le sirve para hablar en sordina sobre la última dictadura militar. La asociación con el nazismo cierra este sistema acerca de momentos históricos en apariencias distantes, pero íntimamente asociados. Un factor que todos tienen en común es la eugenesia, la obsesión de pureza étnica o cultural como excusa para la eliminación de ciertos grupos sociales. La elección de un territorio favorecido por sus bellezas naturales, al igual que en la novela de Figueras, disimula de manera insidiosa un sistema político perverso.

La vinculación con los cuentos de hadas a partir del paisaje, con sus bosques, montañas y lagos, apunta por otro lado a poner al descubierto un discurso disciplinador que absorbemos desde la infancia y que tiende a moldear las subjetividades de manera eficaz. Este sistema define con claridad a aquellos cuerpos que son deseables y aquellos que no, y los separa de manera taxativa. Instaura a partir de esta delimitación un determinado orden social, como ya fue mencionado en la introducción. El título de la novela, Wakolda, alude a una muñeca de rasgos indígenas, hecha con madera de incienso y restos de tela. A su manera, es muy bella. Pero es el reverso de Herlitzka, la muñeca aria, europea, manufacturada con una maestría mayor, hecha de porcelana, con ojos de vidrio, cabellos naturales. En fin, lo que se suele considerar como paradigma de la perfección. La protagonista de la novela es Lilith ${ }^{7}$, una niña, más bien en el umbral hacia la adolescencia, que padece de una deformidad. Lilith nació sietemesina y sería también perfecta, de no ser demasiado pequeña para su edad. Su cuerpo produce un efecto perturbador. La niña es definida en el relato como "un personaje mitológico, mezcla de ninfa y de duende" (Puenzo 21). Al igual que Wakolda, también es agraciada aunque no responda a cierto ideal de belleza.

De todos modos, esta niña es monstruosa por más de una razón. Su malformación física la coloca en el terreno de la diferencia, una vez que lo que se considera normal ha delimitado sus parámetros. Para contrarrestar esto, se la describe como sensible e inteligente. No le falta empatía para ponerse del lado de los más desfavorecidos, como se ve en su trato con la familia de origen mapuche. Por eso resulta doblemente perturbadora la trama de seducción entre ella y Mengele, al que en la novela no se menciona como tal sino siempre como José ${ }^{8}$. El segundo aspecto de la monstruosidad, el más inquietante,

7 El nombre escogido para la niña, Lilith, es muy significativo por el mito al que hace referencia, la mujer que desde el inicio de los tiempos se rebela ante el poder patriarcal y corporiza la transgresión. Este mito se completa en la novela con el hecho de que la madre se llama Eva, la segunda mujer de Adán, que logra desbancar a Lilith de la historia y confinarla al terreno del mito.

8 El personaje de José aparece identificado en una escena con el cuento "El flautista de Hamelín". En un momento 
radica en la sexualidad en ciernes de esta niña, que como la Caperucita de los cuentos orales tradicionales (no la de Perrault o los hermanos Grimm) ${ }^{9}$, no le teme al lobo sino que se lanza a jugar con él. En el primer encuentro entre Lilith y José se pone en escena lo que Luisa Valenzuela concentra en un párrafo de su cuento "Si esto es la vida, yo soy Caperucita Roja", la niña que muestra temeridad precisamente porque teme, y porque desea lo que teme: “¿Dónde vas, Caperucita, con esa canastita tan abierta, tan llena de promesas?, me pregunta el lobo, relamiéndose las fauces. Andá a cagar, le contesto, porque me siento grande, envalentonada. Y reanudo mi viaje" (Valenzuela, Cuentos completos 64). Lilith responde con precisión al modelo de Caperucita que nos presenta Valenzuela. Y también se ve en el lazo generacional conflictivo entre madres e hijas. Primero, la lucha entre Eva, la madre de Lilith, y su propia madre alemana. Luego entre Eva y Lilith. Este sistema genealógico materializa la oscilación ancestral entre obedecer los mandatos y transgredirlos, como pasos fundamentales para la configuración de la subjetividad adulta. En ese acto de seducción, la niña pierde tanto como gana. Porque si bien lo que está en juego es la asunción de dicha subjetividad y el control sobre el propio cuerpo, no puede rozar el mal sin quedar lastimada. Lo que Lilith finalmente negocia y se deja arrebatar no es la virginidad, algo más bien sugerido, sino la inocencia que ella corrompe al convertirse en cómplice de su abusador. Se supone que la muñeca Wakolda lleva en su vientre un talismán que logra cumplir los deseos. Ese talismán, que es robado por José, en cierta medida resulta eficiente, ya que parece cumplir el deseo de Lilith. Ahí radica gran parte de la ambigüedad del texto, que se detiene en los pliegues de la subjetividad infantil en lugar de mostrarla como un espacio diáfano y claro.

Volviendo a la noción de monstruo que desarrolla Rosi Braidotti, esta pensadora nos recuerda que lo interesante de dichas figuras es que, al prestarse a un juego de la imaginación en donde se asumen todo tipo de ambivalencias, resultan epistemofílicas. No solo expresan la curiosidad acerca de los orígenes de los cuerpos anómalos, sino que además producen un conocimiento (138). Los discursos alrededor del monstruo han estado puestos al servicio de organizar tanto científica como socialmente la percepción de las diferencias corporales. Pero además, su etimología misma envía a la noción de advertencia (135), lo que en el texto de Puenzo se aplica cabalmente y aparece trabajado a partir de una cuestión de género sexual. Los discursos acerca de lo que origina un cuerpo monstruoso se ligan a las prácticas sexuales, a sus excesos, en particular en lo que involucra al género femenino. Apunta a lo que Braidotti llama la cuestión de la "imaginación maternal” (141). Es decir, la operación discursiva que tendió a colocar en el poder de la imaginación de la mujer la capacidad de generar monstruos. En la novela, no se intenta

dado José está leyendo ese cuento al hermano menor de Lilith, una forma de citar la intertextualidad. Resulta claro que él actúa como el flautista, encantando a los personajes que lo rodean con sus buenos modales y sus argumentos seudocientíficos, y el gesto de apropiarse de los niños mediante la seducción.

9 La primera versión que se tiene del cuento tal como lo conocemos proviene de Charles Perrault que la fija en el año 1697. Bettelheim hace notar que la historia en sí es muy antigua, de hecho podría remontarse al relato de Cronos devorando a sus hijos. Menciona también una historia en latín de 1023, Fecunda ratis de Egberto de Lieja (186). 
explicar el origen de la deformación de Lilith, pero es evidente que la monstruosidad queda ligada a las mujeres de la familia. Es el médico, el científico, el que viene a corregir esa malformación. También interviene en el nacimiento de los hermanos mellizos de Lilith y experimenta con ellos. José corporiza a la figura del hombre de ciencias acuñada en el siglo XIX, que Agamben ve como central del horizonte biopolítico de la modernidad (Agamben, Homo sacer 202). Retomar un personaje ligado a la experiencia que significó el nazismo queda entonces plenamente justificado. Cobra espesor en el marco de la tesis de Agamben acerca de la biopolítica, cuando considera al campo de concentración, en tanto que espacio puro de la excepción, como el paradigma oculto del espacio político de la modernidad (156). Según Agamben, el nuevo sujeto de la política en la democracia moderna es el corpus, lo cual significa colocar en el centro no la vida cualificada del ciudadano (bios) sino la "nuda vida en su anonimato" (zoe) (157-8). Si el nacimiento se vuelve el "portador inmediato de la soberanía" (163), entonces el territorio es el que pasará a determinar el sistema de límites y exclusiones. Esto se aplica a los cuerpos individuales, que ya no estarán subsumidos más que a esa existencia nuda. Una de las consecuencias que puntualiza Agamben es que la biopolítica moderna genera la permanente necesidad de definir el umbral que articula y separa lo que está adentro y lo que está afuera de la vida, tendencia que él ve llevada hasta la exasperación (166). Esa exasperación, a fuerza de repetición, se nos vuelve cotidiana, salvo en algunos momentos de paroxismo como el planteado por el sistema nacional-socialista.

El personaje de Lilith, esta niña monstruosa, genera una serie de líneas de fuga que desafían la norma de lo considerado humano, su legibilidad y sus usos (Giorgi 323). En ese sentido, permite plantear nuevas formas de lo humano. En su exceso de vida, se opone a los intentos del poder soberano de normalizar y de jerarquizar los cuerpos. Su mirada, que es desafiante de principio a fin, inquieta porque se planta como la posibilidad de desestructurar los impulsos eugenésicos de la modernidad cientificista. La novela cierra, a pesar de todo, con un mensaje enigmático: José se lleva el talismán misterioso de Wakolda y deja en su interior un puñado de ojos de vidrio, esos ojos perfectos de sus muñecas pesadillescas. Este gesto, que dentro de un contexto de poder patriarcal puede ser entendido como señal de castigo por la curiosidad, puede ser leído de otra manera, si se sigue la lectura a contrapelo que se viene planteando. Seguir el propio deseo puede costar un alto precio, algo que Lilith tiene que aprender. Pero sin fisgoneo, no hay aventura, no hay posibilidad de contar una historia, de hacerse de la propia voz. Algo que las mujeres saben desde Pandora en adelante.

\section{"El deseo crece"}

El texto de Lina Meruane es más complejo. Para comenzar, desestabiliza la convención genérica. Antes que una novela, es un conjunto de relatos intercalados, hilvanados entre sí, pero que pueden leerse de manera más o menos independiente. Hay dos líneas narrativas 
entrecruzadas, demarcadas mediante una grafía distinta y otros recursos que evocan el estilo de los cuentos infantiles. La línea en donde se siguen las peripecias de Hildeblanca e Hildegreta remite de manera más evidente a una reinterpretación de los cuentos de hadas, en una tesitura muy semejante a Cuentos de Hades de Luisa Valenzuela. Los relatos tradicionales son deformados, tal como se ve en la parodia significada por los nombres de las infantas del título, pero siguen siendo reconocibles. Desfilan de diversas maneras numerosos cuentos fijados por Charles Perrault junto con otro tipo de narraciones y leyendas ligadas a lo que hoy se considera literatura infantil ${ }^{10}$. Se evocan también el tono y la iconografía de los libros de caballería ibéricos, muy populares entre los siglos XV y XVI.

En el gesto de reciclado de los cuentos de hadas, hay varios elementos que ambas autoras comparten. En primer lugar, la cuestión del bosque como un espacio de incursión ajeno, pero que representa "el camino de la vida" (Muñoz 233). No solo por ser un lugar de negociación, con todos los aspectos positivos y negativos que eso implica, sino también por estar ligado a la administración del cuerpo. Esto se vincula por lo tanto a la manera en que se trabajan las imágenes que designan fluidos (sangre, esperma, saliva, etcétera), así como a las dinámicas de metamorfosis y transmigración. Se liga claramente a la noción de lo abyecto, codificada por Julia Kristeva como aquello que perturba una identidad, un sistema, un orden (Kristeva 11). El tercer elemento es el de la animalidad, en tanto que es parte constitutiva de la subjetividad humana. Aparece utilizada junto con el tópico del doble, evidente también en la estructura de la obra, en los personajes duplicados y en los numerosos ejemplos de transmutación. Circulan hormigas, ratas, perros y el consabido lobo, que funcionan como ese otro que es parte del sí mismo. No podía faltar tampoco la figura de la bruja, tan recorrida por Luisa Valenzuela, que se vincula con un tipo de sabiduría ancestral, ligada al universo femenino, marginalizada de la cultura hegemónica, y que emerge siempre como un retorno de lo reprimido.

El texto en sí mismo es un cuerpo proliferante y monstruoso, que se regodea en la mezcla y en la transformación. En parte tal vez se deba a lo que Walter Benjamin describe como algo inherente al libro infantil:

No es que las cosas emerjan de las páginas, al ser contempladas por el niño, sino que este mismo entre en ellas, como celaje que se nutre del policromo esplendor de ese mundo pictórico. Ante su libro iluminado, practica el arte de los taoístas consumados; vence el engaño del plano y, por entre tejidos de color y bastidores abigarrados, sale a un escenario donde vive el cuento de hadas (73).

El relato infantil aparece como un espacio separado gracias a la estructura de la duplicación. Por otro lado logra colarse y contaminar topografías más conocidas: las calles

10 De Perrault, cuyo texto es elevado al nivel de Biblia en la escena del juicio (a Hildegreta se le pide que jure sobre el libro de Perrault), se toman "Barba Azul", "Caperucita roja", "La bella durmiente", "La Cenicienta", todos publicados como Historias y Cuentos de Tiempos Pasados en 1697. Pero también están evocados El príncipe y el mendigo (1881) de Mark Twain, la leyenda de Rómulo y Remo, Pinocchio (1882-1983) de Carlo Collodi, "Blancanieves" de los hermanos Grimm. El primer texto hace pensar en Alicia en el País de las Maravillas de Lewis Caroll de 1865. 
de la ciudad moderna desfiguradas por el deambular de estos personajes. Pueden leerse referencias veladas a cuestiones políticas, muy en sordina, como un fondo que aletea y que irrumpe en el momento menos esperado. No obstante queda claro que la invitación planteada por el texto es dejarse arrastrar por la corriente de ese mundo pictórico.

La acción se dispara con un acto autoritario, la decisión del Rey de usar a las infantas como objeto de intercambio, siguiendo la lógica de un sistema en el que las mujeres cumplen la función de mercancía. Esto motiva la huida de las infantas hacia el bosque y el comienzo de sus aventuras. Sin embargo, la crítica a un sistema patriarcal no se cierra sobre sí misma, sino que da pie a una reflexión sobre la sexualidad en su más amplio espectro. Al igual que en Wakolda, adquieren un rol central el erotismo infantil y la asunción del deseo con todas sus implicancias. Las infantas va un poco más allá, porque despliega todo el arco de las sexualidades no hegemónicas, que van desde el incesto, pasando por el deseo homosexual hasta la pederastia, en todas las combinaciones posibles: padres que desean a hijos e hijas, hijas que añoran a sus padres, hermanas que se desean entre sí, como las dos infantas. En ese sentido es un texto fuertemente queer. Y es que de lo que se está hablando es de la ubicuidad del deseo, de su permanente movilidad y capacidad de transformación. Responde a la idea de que el cuerpo no es otra cosa que un límite poroso, que se constituye a partir de un sistema relacional como consecuencia de quedar, según palabras de Judith Butler, en "una trayectoria del deseo en la cual uno es sacado de sí y resituado irreversiblemente en el campo de los otros" (Butler, Deshacer el género 46).

En Las infantas los cuerpos se hacen y deshacen delante de los ojos del lector, con una ductilidad insospechada. Materializan también la noción del devenir deleuziano en todas sus posibilidades: devenir-animal, devenir-mujer, devenir-imperceptible. Las permanentes metamorfosis del relato no funcionan en términos de arquetipos; se sale de toda serie que implique una relación de progresión-regresión. Apunta más bien a lo que se evita mediante el devenir, aquello que según Deleuze y Guattari pertenece al orden de la filiación. El devenir se corresponde entonces con el orden de la alianza (245), o de una involución que no es regresiva sino creadora. Funciona también en la novela la dinámica del comportamiento del devenir que actúa por epidemia, por contagio. Tal y como describen Deleuze y Guattari, la novela es un muestreo de un conjunto de procedimientos: "Nosotros oponemos la epidemia a la filiación, el contagio a la herencia, el poblamiento por contagio a la reproducción sexuada, a la producción sexual. Las bandas, humanas y animales, proliferan con los contagios, las epidemias, los campos de batalla y las catástrofes" (247). Las infantas, en un principio dos, se van multiplicando hacia esa manada de personajes que solo en apariencias emergen de las páginas abiertas de un libro de Perrault. Entran y salen de cuerpos ajenos, porque los cuerpos ya no retienen. Las estructuras familiares quedan totalmente obsoletas. El triángulo edípico no se rearma, porque la línea jerárquica es desmontada en favor de una fluidez ininterrumpida. Si el recuerdo siempre tiene una función de reterritorialización, la dinámica del devenir se expresa también en la antimemoria, en esa especie de amnesia en la que están sumidas las dos infantas, empezando por Hildeblanca, pero en la que parecen naufragar todos los personajes. 
Puestos a circular, los relatos se fagocitan con la velocidad de una corriente que no da tiempo para escindirlos. Sean los cuentos de hadas o sus primas-hermanas, las novelas de caballerías, o los mitos que quedaron codificados a partir de la mitología griega, lo cierto es que la dinámica de la metamorfosis pasa del nivel del enunciado al de la enunciación. Actúa como un sistema de espejos enfrentados, que no permite al lector poner el pie ni en uno ni en el otro. La metamorfosis cumple entonces con el papel que le adjudica la narrativa postmoderna de perturbar al hombre al sacarlo de su centro, y burlar de esa manera sus "prerrogativas antropocéntricas" (García 22). La herida se vuelve a todas luces narcisista. Esa herida que está en el comienzo de la obra, señalada en el epígrafe de Severo Sarduy, que se amplifica mediante los procedimientos del devenir, resulta una estocada mortal en el cuento que cierra el volumen, y que nos conduce a un cierto principio, el relato de Edipo y la Esfinge. No se trata solamente de narrar bajo diversas variaciones el momento de fuga desde la casa del padre por parte de la hija (Acuña), sino de desbaratar la ilusión de ese relato que ha servido para disciplinar las subjetividades mediante la matriz de una heterosexualidad fuera de todo cuestionamiento.

\section{Conclusiones}

El tópico de la fuga hacia el bosque aparece en las tres obras. No solo porque supone poner en movimiento la acción de iniciar el camino de la experiencia, lo que se introduce a través de la estilización bajo diversas formas del personaje de Caperucita Roja. Es parte del procedimiento de recrear un universo extraño, arcaico, misterioso. El retorno a los paisajes de la infancia supone la intención de configurar un tipo de mirada singular, ligada a una etapa que suele ser codificada como un comienzo. Volvemos entonces a Agamben y al lazo que él establece entre infancia y experiencia para definir ese estadio que antecede o que excede al lenguaje (71). Lo que interesa resaltar aquí es la posibilidad que abre de entender otra forma de temporalidad. La infancia ha sido también definida a partir de una manera peculiar de experimentar el tiempo, que nos recuerda a los adultos la convivencia de temporalidades divergentes. La imagen del niño que juega ha sido utilizada para hablar de una forma del tiempo que en la Grecia clásica era denominada con el término aión (Agamben 105. Kohan 92-4). Se aplicaba a la intensidad del tiempo de la vida, y se diferenciaba en ese sentido tanto de cronos el tiempo conmensurable, como de kairós -el acontecimiento súbito-. Esta noción del tiempo como aión es recuperada para resaltar la idea de que la infancia es una instancia presente y activa de toda subjetividad, y no solo un lugar inaugural y alejado en la línea temporal. La reflexión de Agamben sobre la infancia como comienzo adquiere su sentido para pensar los límites del lenguaje, sobre todo en lo que se refiere a su nexo con la noción de experiencia. La infancia actúa en tanto umbral como una experiencia del límite trascendental del lenguaje. Le es esencial en la medida en que demarca los límites del mismo, y así evita que el lenguaje se instituya como totalidad y verdad (Agamben 70). Vendría a ser ese exterior constitutivo del lenguaje que 
trabaja en su permanente reformulación, que impide que se cierre sobre sí mismo y que clausure sus sentidos. El bosque, como paisaje de la infancia, es retomado porque exhibe una estructura de pliegue, que aúna las nociones de altura y abismo, de profundidad, de permanente oposición entre fondo y forma. No se ve todo lo que circula en él; esconde más de lo que muestra. Esto lo convierte en un espacio cuyas características principales son la ambigüedad y el peligro. Si nunca resultó difícil identificar a este paisaje como una figura del subconsciente, las novelas analizadas lo plantean ahora como una máquina deseante. En las tres obras, las niñas aparecen como seres abyectos. Su carácter de anómalas queda subrayado en la medida en que son habitantes de esos bosques. Si bien hay una gradación entre una obra y otra, sobre todo en lo que concierne al tema de la sexualidad infantil (básicamente obturado en la novela de Figueras, lo que no nos parece casual, sino central en las otras dos), las niñas corporizan los puntos de fuga, o ese pliegue en donde pierden sentido las taxonomías. Son esas máquinas deseantes que arremeten sin inhibiciones y desarticulan lo establecido.

El enajenamiento se aplica antes que nada a los cuerpos que desafían la norma. El objetivo en los tres casos parece compartir la premisa planteada por Judith Butler, a quien preocupa de modo fundamental un sistema de exclusiones mediante el que se definen cuáles sean los cuerpos considerados aptos para la inteligibilidad de lo humano. Darle forma a la aberración ofrece la posibilidad de replantear la persona en otros términos y generar un mayor grado de habitabilidad para la misma. Parece ser necesario que lo humano se convierta en algo extraño a sí mismo, en algo incluso monstruoso, afirma Butler (271). Volver a la infancia, no es pues un asunto menor. Implica en primer lugar examinar el origen de los hábitos de sujeción que estructuran nuestro sistema normativo. Recuperar la fantasía como motor de cambio también es una forma de reconocer la arbitrariedad y la contingencia de ese sistema: "La fantasía es lo que nos permite imaginarnos a nosotros mismos y a otros de manera diferente; es lo que establece lo posible excediendo lo real; la fantasía apunta a otro lugar y, cuando lo incorpora, convierte en familiar ese otro lugar" (Butler 51). Se aplica en primera instancia a una comprensión matizada de los cuerpos. Esta se percibe como urgente ante el avance de una obsesión eugenésica contemporánea que aparece velada, pero no por eso es menos eficaz. Como apunta Paula Sibilia, si bien esta disciplina perdió su legitimidad a causa del paroxismo a la que fue conducida por el nazismo, se trata de un gesto de corte fáustico que atraviesa todo el siglo XIX y el XX. Pero no desaparece, sino que emerge en el siglo XXI mediante la "alquimia de los genes y los bits" (136), nuevos experimentos y obsesiones que nos asombran (o no tanto) desde las páginas cotidianas de los diarios. No resulta descolocado entonces que Puenzo retorne al episodio nacional-socialista y nos recuerde su ligazón con nuestra historia sudamericana. Los infantes, como emergentes de la anormalidad y de lo que la sociedad intenta aislar para controlar mejor, aparecen en la literatura como formas desafiantes, doblemente ominosas por el sistema de dobleces que conlleva hablar desde lo inefable, desde ese lugar en donde no impera la lógica sino la fantasía. Miranda, Lilith, la dupla Hildegreta/ Hildeblanca (dos caras de la misma moneda), niñas monstruosas, apelan a la mirada de 
la infancia que está presente en cada lector y lo obligan a deslizarse en esa escenografía de tejidos de color y bastidores abigarrados que nos es familiar pero a la vez siniestra. Ese cambio de perspectiva está puesto al servicio de una indispensable revisión no solo de las constelaciones familiares, sino del sistema que permite hacer inteligibles a los cuerpos, para concebirlos de una manera más fluida, más acorde con los desafíos del mundo presente.

\section{Referencias}

Acuña, Ezequiel. “Juguemos en el bosque”. Página/12, 20 de junio 2010: Radar Libros. < http://www.pagina12.com.ar/diario/suplementos/libros/10-3880-2010-06-20. html $>$. Fecha de ingreso: 4 de junio de 2012. Sitio web.

Agamben, Giorgio. Homo Sacer. El poder soberano y la nuda vida. Valencia: Pre-Textos, 1998. Medio impreso.

---. Infancia e historia. Destrucción de la experiencia y origen de la historia . Buenos Aires: Adriana Hidalgo, 2007. Medio impreso.

Benjamin, Walter. Escritos. La literatura infantil, los niños y los jóvenes. Buenos Aires: Nueva Visión, 1989. Medio impreso.

Bettelheim, Bruno. Psicoanálisis de los cuentos de hadas. Buenos Aires: Crítica, 2011. Medio impreso.

Braidotti, Rosi. "Mothers, Monsters, and Machines". Nomadic Subjects. Embodiment and sexual difference in contemporary feminist theory. New York: Columbia University Press, 1994. 59-79. Medio impreso.

---. "Signs of Wonder and Traces of Doubt: on Teratology and Embodied Differences". Between Monsters, Goddesses and Cyborgs. Eds. Nina Lykke y Rosi Braidotti. London \& New Jersey: Zed Books, 1996. 135-152. Medio impreso.

Bustelo, Eduardo. El recreo de la infancia. Argumentos para otro comienzo. Buenos Aires: Siglo XXI, 2007. Medio impreso.

Butler, Judith. Deshacer el género. Barcelona: Paidós, 2006. Medio impreso.

Chevalier, Jean y Alain Gheerbrant. Dictionnaire des Symboles. Paris: Robert Laffont/ Jupiter, 1982. Medio impreso.

Deleuze, Gilles y Felix Guattari. Mil mesetas. Capitalismo y esquizofrenia. Valencia: PreTextos, 2002. Medio impreso.

Detrez, Christine. La construction sociale du corps. Paris: Édition du Seuil, 2002. Medio impreso.

Díaz Rönner, María Adelia. "La literatura infantil : territorio de subversiones”. La cultura de los géneros. Coord. Lisa Bradford. Rosario: Beatriz Viterbo, 2001. 113-127. Medio impreso.

Figueras, Marcelo. La batalla del calentamiento. Buenos Aires: Alfaguara, 2006. Medio impreso.

Foucault, Michel. Los anormales. Buenos Aires: FCE, 2000. Medio impreso. 
Friera, Silvina. "Necesité tres novelas para resolver mis obsesiones. Entrevista a Marcelo Figueras". Página/12, 24 de diciembre 2006: Cultura \& Espectáculos. <http://www. pagina12.com.ar/diario/suplementos/espectaculos/4-4903-2006-12-24.html>. Fecha de ingreso: 1 de septiembre de 2010. Sitio web.

García, Mariano. "La meta del mito. Imágenes y metamorfosis en la literatura argentina del nuevo milenio". Un corte de género: mito y fantasía. Coord. José Amícola. Buenos Aires: Biblos, 2011. 11-35. Medio impreso.

Giménez, Gilberto. “Cultura, territorio y migraciones. Aproximaciones teóricas”. Alteridade, 11:2, (2001). 5-14. <http://www.rema.org.py/documentos/Cultura,\%20territorio\%20 y\%20migraciones.pdf $>$. Fecha de ingreso: 13 de julio de 2012. Sitio web.

Giorgi, Gabriel. “Política del monstruo”. Revista Iberoamericana Vol. LXXV 227 (2009). 323-329. Medio impreso.

Kohan, Walter O. Infancia, política y pensamiento. Ensayos de filosofía y educación. Buenos Aires: Del Estante Editorial, 2007. Medio impreso.

Kristeva, Julia. Poderes de la perversión. México: Siglo XXI, 2010. Medio impreso.

Meruane, Lina. Las infantas. Buenos Aires: Eterna Cadencia, 2010. Medio impreso.

Muñoz, Willy. "Luisa Valenzuela y la subversión normativa en los cuentos de hadas: 'Si esto es la vida, yo son Caperucita Roja". La palabra en vilo: narrativa de Luisa Valenzuela. Eds. Gwendolyn Díaz y María Inés Lagos. Santiago de Chile: Cuarto Propio, 1996. 221-246. Medio impreso.

Puenzo, Lucía. Wakolda. Buenos Aires: Emecé, 2011. Medio impreso.

Punte, María José. "Perón, personaje de novela”. RILCE. Revista de Filología Hispánica 20.2 (2004). 223-39. Medio impreso.

Roudinesco, Élisabeth. La familia en desorden. Buenos Aires: FCE, 2010. Medio impreso.

Sibilia, Paula. El hombre postorgánico: cuerpo, subjetividad y tecnologías digitales. Buenos Aires: FCE, 2009. Medio impreso.

Valenzuela, Luisa. "Ventana de hadas". Peligrosas palabras. Buenos Aires: Tema Grupo, 2001. 211-215. Medio impreso.

---. Cuentos completos y uno más. México: Alfaguara, 1998. Medio impreso. 